\title{
Can bronchodilators improve exercise tolerance in COPD patients without dynamic hyperinflation?*
}

\author{
Os broncodilatadores podem melhorar a tolerância ao exercício na \\ ausência de hiperinsuflação dinâmica em pacientes com DPOC?
}

\author{
Maria Enedina Aquino Scuarcialupi, Danilo Cortozi Berton, Priscila Kessar Cordoni, \\ Selma Denis Squassoni, Elie Fiss, José Alberto Neder
}

\begin{abstract}
Objective: To investigate the modulatory effects that dynamic hyperinflation (DH), defined as a reduction in inspiratory capacity (IC), has on exercise tolerance after bronchodilator in patients with COPD. Methods: An experimental, randomized study involving 30 COPD patients without severe hypoxemia. At baseline, the patients underwent clinical assessment, spirometry, and incremental cardiopulmonary exercise testing (CPET). On two subsequent visits, the patients were randomized to receive a combination of inhaled fenoterol/ipratropium or placebo. All patients then underwent spirometry and submaximal CPET at constant speed up to the limit of tolerance (Tlim). The patients who showed $\Delta \mathrm{lC}$ (peak-rest) $<0$ were considered to present with $\mathrm{DH}(\mathrm{DH}+)$. Results: In this sample, 21 patients (70\%) had $\mathrm{DH}$. The $\mathrm{DH}+$ patients had higher airflow obstruction and lower Tlim than did the patients without $\mathrm{DH}(\mathrm{DH}-)$. Despite equivalent improvement in $\mathrm{FEV}_{1}$ after bronchodilator, the $\mathrm{DH}$ - group showed higher $\Delta \mathrm{IC}$ (bronchodilator-placebo) at rest in relation to the $\mathrm{DH}+$ group $(\mathrm{p}<0.05)$. However, this was not found in relation to $\Delta \mathrm{IC}$ at peak exercise between $\mathrm{DH}+$ and $\mathrm{DH}-$ groups $(0.19 \pm 0.17 \mathrm{~L}$ vs. $0.17 \pm 0.15 \mathrm{~L}, \mathrm{p}>0.05)$. In addition, both groups showed similar improvements in Tlim after bronchodilator (median [interquartile range]: 22\% [3-60\%] vs. 10\% [3-53\%]; $p$ > 0.05). Conclusions: Improvement in TLim was associated with an increase in $1 \mathrm{C}$ at rest after bronchodilator in $\mathrm{HD}$ - patients with COPD. However, even without that improvement, COPD patients can present with greater exercise tolerance after bronchodilator provided that they develop DH during exercise.
\end{abstract}

Keywords: Pulmonary disease, chronic obstructive; Bronchodilator agents; Exercise test; Exercise tolerance; Inspiratory capacity.

\section{Resumo}

Objetivo: Investigar os efeitos moduladores da hiperinsuflação dinâmica (HD), definida pela redução da capacidade inspiratória $(\mathrm{Cl})$, na tolerância ao exercício após broncodilatador em pacientes com DPOC. Métodos: Estudo experimental e randomizado com 30 pacientes com DPOC sem hipoxemia grave. Na visita inicial, os pacientes realizaram avaliação clínica, espirometria e teste de exercício cardiopulmonar (TECP) incremental. Em duas visitas subsequentes, os pacientes foram randomizados para receber uma combinação de fenoterol/ipratrópio ou placebo e, em seguida, realizaram espirometria e TECP com velocidade constante até o limite da tolerância (Tlim). Os pacientes com $\Delta \mathrm{Cl}$ (pico-repouso) < 0 foram considerados com HD (HD+). Resultados: Nesta amostra, 21 pacientes (70\%) apresentaram HD. Os pacientes HD+ apresentaram maior obstrução ao fluxo aéreo e menor Tlim do que os pacientes sem HD (HD-). Apesar de ganhos equivalentes de $\mathrm{VEF}_{1}$ após broncodilatador, o grupo $\mathrm{HD}$ - apresentou maior $\Delta \mathrm{Cl}$ (broncodilatador-placebo) em repouso em relação ao grupo $\mathrm{HD}+(\mathrm{p}<0,05)$. Entretanto, isso não ocorreu com a $\Delta \mathrm{Cl}$ no pico do exercício entre os grupos $\mathrm{HD}+\mathrm{e} \mathrm{HD}-(0,19 \pm 0,17 \mathrm{~L}$ vs. 0,17 $\pm 0,15 \mathrm{~L}$; $p>0,05)$. Similarmente, ambos os grupos apresentaram melhoras equivalentes do Tlim após broncodilatador (mediana [intervalo interquartílico]: 22\% [3-60\%] e 10\% [3-53\%]; p > 0,05). Conclusões: A melhora da Cl em repouso após broncodilatador associou-se com ganho de tolerância ao esforço mesmo nos pacientes com DPOC que não apresentem HD. Por outro lado, pacientes sem melhora da $\mathrm{Cl}$ em repouso ainda podem obter beneficio funcional com o broncodilatador desde que apresentem HD no exercício.

Descritores: Doença pulmonar obstrutiva crônica; Broncodilatadores; Teste de esforço; Tolerância ao exercício; Capacidade inspiratória.

*Study carried out at ABC School of Medicine, Santo André, Brazil.

Correspondence to: José Alberto Neder. Richardson House, 102 Stuart Street, Kingston, K7L 2V6, ON, Canada.

Tel. 1613 549-6666 (extension 2255). Fax: 1613 533-6695. E-mail: nederalb@gmail.com

Financial support: None.

Submitted: 25 October 2013. Accepted, after review: 2 December 2013. 


\section{Introduction}

Lung hyperinflation is a crucial mechanism of dyspnea on exertion in COPD patients. ${ }^{(1-3)}$ Bronchodilator therapy can reduce static and dynamic lung volumes during exercise, increasing exercise tolerance in such patients. ${ }^{(4,5)}$

The current concept of the mechanisms whereby bronchodilators can improve exercise tolerance in patients with COPD focuses on the ability to reduce the rate of increase in end-expiratory lung volume (EELV) as the exercise progresses, i.e., a reduction in dynamic hyperinflation (DH). ${ }^{(1,6)} \mathrm{In}$ practice, DH can be estimated by serial measurements of inspiratory capacity (1C), ${ }^{(6-8)}$ which reflects EELV, given that TLC does not change significantly with exercise. ${ }^{(9)}$ An alternative (or complementary) mechanism of action of bronchodilators is reduction in operating lung volumes at rest, i.e., pre-exercise deflation..$^{(10,11)}$ In this case, patients can benefit from bronchodilator use even in the absence of $\mathrm{DH}$, given that there are "volume reserves" to be consumed during exercise. In any event, with the use of a bronchodilator, all patients can achieve the same EELV at peak exercise, albeit by different mechanisms (i.e., either by a reduced rate of $\mathrm{DH}$ or by reduced static hyperinflation).

Our objective was to investigate whether the administration of a bronchodilator results in improvement in exercise capacity in patients with moderate to severe COPD, despite the fact that bronchodilators act predominantly on exercise-related static hyperinflation or $\mathrm{DH}$. The confirmation of this hypothesis would support the notion that measurements of lung hyperinflation at rest and during exercise are complementary in the evaluation of the effects of bronchodilators on exercise tolerance in such patients.

\section{Methods}

We studied a convenience sample of 30 patients diagnosed with COPD in accordance with the Global Initiative for Chronic Obstructive Lung Disease criteria. ${ }^{(12)}$ The patients were over 40 years of age and had a post-bronchodilator $\mathrm{FEV}_{1}<70 \%$ of predicted, an $\mathrm{FEV}_{1} / \mathrm{FVC}$ ratio $<$ $70 \%$, and a smoking history of more than 20 pack-years. Patients were recruited from among those treated at the COPD outpatient clinic or pulmonary rehabilitation center of our institution. The exclusion criteria were as follows: severe resting hypoxemia $\left(\mathrm{SpO}_{2}<90 \%\right)$; comorbidities contributing to dyspnea and exercise limitation; COPD exacerbation or respiratory infection in the previous month; and contraindication to clinical exercise testing. The study project was approved by the local research ethics committee. All participants gave written informed consent.

At the initial visit, all of the patients who remained eligible after their clinical and functional characteristics had been determined by spirometry performed before and after the administration of $400 \mu \mathrm{g}$ of inhaled albuterol underwent incremental symptom-limited cardiopulmonary exercise testing (CPET). The patients returned for two more experimental visits (3-7 days apart), during which they randomly received placebo or $0.5 \mathrm{~mL}$ of fenoterol hydrobromide $(0.5 \%$ Berotec ; Boehringer Ingelheim do Brasil, São Paulo, Brazil) with $2 \mathrm{~mL}$ of ipratropium bromide (0.025\% Atrovent ${ }^{\oplus}$; Boehringer Ingelheim do Brasil) diluted in $5 \mathrm{~mL}$ of saline for nebulization. Within 30 min after nebulization, spirometry was performed, being followed by submaximal CPET at constant speed (i.e., at $70-80 \%$ of the maximum speed achieved during incremental CPET at the initial visit). During submaximal CPET at constant speed, serial measurements of $\mathrm{IC}$ were made every 2 min (from rest to peak exercise) in order to assess operating lung volumes during exercise. The study design is shown in Figure 1.

All spirometric tests were performed with a Koko $\mathrm{PFT}^{\circledR}$ spirometer (PDS Instrumentation, Inc., Louisville, CO, USA). The variables measured were FVC, $\mathrm{FEV}_{1}, \mathrm{FEV}_{1} / \mathrm{FVC}$, and $\mathrm{IC}$. Maximal voluntary ventilation was estimated by multiplying FEV by 37.5. ${ }^{(13)}$ Participants completed at least three slow, forced expiratory maneuvers, considered acceptable and reproducible.

CPET was performed with the patients connected to a Vmax 229c $\mathrm{c}^{\text {mi }}$ system (Vyasis, Yorba Linda, CA, USA) via a face mask and walking on an ATL treadmill (Inbrasport, Porto Alegre, Brazil). During incremental CPET, after 2 min at a constant speed of $1.6 \mathrm{~km} / \mathrm{h}$ without inclination, the speed was increased every $1 \mathrm{~min}$ by 0.3 $\mathrm{km} / \mathrm{h}, 0.5 \mathrm{~km} / \mathrm{h}$, or $0.8 \mathrm{~km} / \mathrm{h}$ depending on the functional capacity of the patient, as determined by the examiner prior to the test. During the tests, the patients were instructed to hold the side bars only when needed (dizziness and loss 


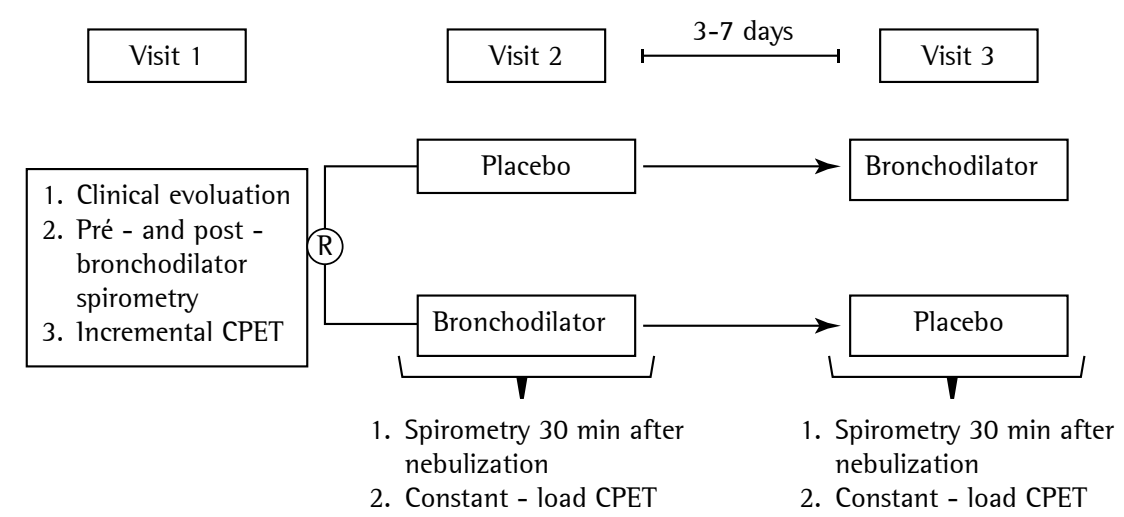

Figure 1 - Study design. BD: bronchodilator; CPET: cardiopulmonary exercise testing; and R: randomization.

of balance, among others). During submaximal CPET at constant speed, after a 2-min warm-up phase, the work rate was suddenly increased to a speed corresponding to $70-80 \%$ of the maximum speed achieved during incremental CPET, and the patients were encouraged to walk until they reached their limit of tolerance (Tlim, s). At the end of the initial phase and every 2 min during the tests, the patients were asked about the intensity of dyspnea and leg fatigue, by means of the modified Borg scale. ${ }^{(14)}$

The following variables were measured (breath by breath) and expressed as mean 15-s time: oxygen consumption, in $\mathrm{mL} / \mathrm{min}$, under standard temperature, pressure dry conditions; minute ventilation, in $\mathrm{L} / \mathrm{min}$, under body temperature, pressure saturated conditions; tidal volume, in $\mathrm{L}$; and RR, in breaths/min. The R-R interval on a 12-lead electrocardiogram was used in order to determine HR (in bpm), and pulse oximetry with an Onyx $9500^{\text {min }}$ pulse oximeter (Nonin, Plymouth, $\mathrm{MN}, \mathrm{USA}$ ) was used in order to estimate $\mathrm{SpO}_{2}$. We evaluated the dynamic changes in operating lung volumes by serial measurements of $\mathrm{IC}$, assuming that TLC remained constant during exercise. ${ }^{(9)}$ During submaximal CPET at constant speed, two 1C maneuvers were performed at rest, at the end of the initial period and every 2 min after the beginning of the constant speed test, in order to obtain reproducible values $(<10 \%$ difference in relation to the highest value, at each stage). In one of the visits after the administration of placebo (the second or third visit, depending on the randomization), the patients in whom IC at peak exercise was reduced in comparison with $\mathrm{IC}$ at rest were included in the $\mathrm{DH}+$ group. (15) A standardized time point near the end of the test marked "isotime", which was defined as the longest exercise duration common to the two submaximal cardiopulmonary exercise tests performed at constant speed by a given individual.

The data are presented as mean and standard deviation for variables with normal distribution and as median (interquartile range) for those with non-normal distribution. Possible differences between groups were analyzed by unpaired t-test, whereas differences between placebo and bronchodilator use were analyzed by paired t-test. Categorical variables were compared by means of Fisher's exact test. Changes in variables after placebo or bronchodilator use and the interaction depending on the presence or absence of $\mathrm{DH}$ during exercise were analyzed with the general linear model and multivariate repeated measures ANOVA. The Statistical Package for the Social Sciences, version 18.0 (SPSS Inc., Chicago, IL, USA), was used. The level of statistical significance was set at $5 \%$ for all tests $(p<0.05)$.

\section{Results}

Of the 30 patients studied, 21 (70\%) had DH during submaximal CPET at constant speed after placebo administration (the $\mathrm{DH}+$ group) and 9 did not (the $\mathrm{DH}$ - group). There were no statistically significant differences between the $\mathrm{DH}+$ group and the $\mathrm{DH}$ - group regarding age (67.9 \pm 8.4 years vs. $66.1 \pm 8.3$ years), body mass index $\left(26.6 \pm 5.1 \mathrm{~kg} / \mathrm{m}^{2}\right.$ vs. $23.9 \pm 4.4 \mathrm{~kg} /$ $\mathrm{m}^{2}$ ), and maximal exercise capacity, which was determined by measuring oxygen consumption at peak exercise $(1,400 \pm 382$ vs. $1,519 \pm 243$ $\mathrm{mL} / \mathrm{min}$ ).

After placebo administration, the proportion of patients with $\mathrm{FEV}_{1}<50 \%$ of predicted was 
higher in the $\mathrm{DH}+$ group $(18 / 21 ; 86 \%)$ than in the DH-group $(4 / 9 ; 44 \% ; p=0.016$; Table 1$)$. Surprisingly, however, resting $1 \mathrm{C}$ tended to be higher in the $\mathrm{DH}+$ group. All of the patients in the $\mathrm{DH}+$ group had resting $\mathrm{IC}>40 \%$ of predicted, as did $6(67 \%)$ of the 9 patients in the $\mathrm{DH}$ - group $(p=0.02)$. The perception of dyspnea and leg fatigue during exercise was higher in the $\mathrm{DH}+$ group than in the DH-group, whereas Tlim was lower in the former than in the latter (Table 1).

Bronchodilator use resulted in equivalent gains in $\mathrm{FEV}_{1}$ in the $\mathrm{DH}+$ and $\mathrm{DH}$ - groups, with significant increases in flow, which were determined in accordance with the Brazilian Thoracic Association criteria (7/19; 37\% vs. 5/9; $56 \%) .{ }^{(16)}$ However, the variations in resting $1 C$ after bronchodilator use were lower in the $\mathrm{DH}+$ group than in the DH-group (Figure 2A). All of the patients in the $\mathrm{DH}$-group showed an increase in resting $1 C$, as did $9(43 \%)$ of the 21 patients in the $\mathrm{DH}+$ group $(\mathrm{p}<0.01)$, resting $\mathrm{IC}$ values being therefore equalized (Table 1). Our analysis of operating lung volumes after bronchodilator use showed that $\mathrm{IC}$ gains at peak exercise were similar between the two groups (Figure 2B). Although the reduction in dyspnea was greater in the $\mathrm{DH}+$ group than in the $\mathrm{DH}$ - group, both groups showed similar improvements in Tlim with the use of placebo (median [interquartile range]: $22 \%$ [3-60\%] vs. $10 \%$ [3-53\%]; $p>0.05$; Figure 3).

\section{Discussion}

The main finding of the present study was a significant increase in Tlim after bronchodilator use, regardless of the previous pattern of $\mathrm{DH}$ during exercise (Figure 3). The increase in resting $\mathrm{IC}$ after bronchodilator use-reflecting increased static hyperinflation-was associated with increased Tlim in the DH-group. Bronchodilator use improved exercise performance in patients who showed no improvement in resting $\mathrm{IC}$, although only in those who had DH. Therefore, bronchodilator use can improve exercise tolerance in COPD patients by reducing static hyperinflation at

Table 1 - Measurements taken before, during, and after constant-load exercise performed after placebo or bronchodilator use in the groups of patients with and without dynamic hyperinflation during exercise. ${ }^{\mathrm{a}}$

Variables

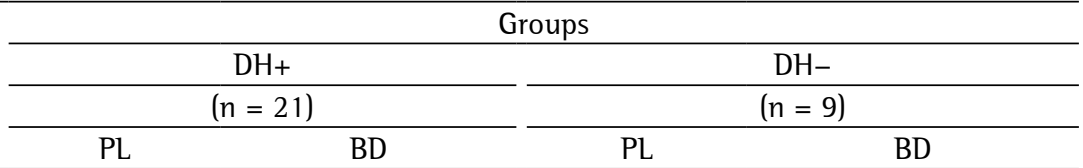

\begin{tabular}{|c|c|c|c|c|}
\hline \multicolumn{5}{|l|}{ Spirometry } \\
\hline $\mathrm{FEV}_{1}, \mathrm{~L}$ & $1.01 \pm 0.26$ & $1.21 \pm 0.36$ & $1.32 \pm 0.41^{*}$ & $1.55 \pm 0.45^{*}$ \\
\hline $\mathrm{FEV}_{1}, \%$ of predicted & $39 \pm 11$ & $46 \pm 13$ & $49 \pm 16^{*}$ & $57 \pm 15^{*}$ \\
\hline FVC, L & $2.18 \pm 0.46$ & $2.52 \pm 0.59$ & $2.44 \pm 0.43$ & $2.77 \pm 0.52$ \\
\hline FVC, $\%$ of predicted & $63 \pm 11$ & $72 \pm 13$ & $70 \pm 18$ & $80 \pm 19$ \\
\hline Resting $\mathrm{IC}, \mathrm{L}$ & $1.83 \pm 0.57$ & $1.89 \pm 0.52$ & $1.47 \pm 0.32^{*}$ & $1.85 \pm 0.44^{* * * * * * *}$ \\
\hline \multicolumn{5}{|l|}{ Isotime of exercise } \\
\hline IC, $\mathrm{L}$ & $1.50 \pm 0.45$ & $1.70 \pm 0.51$ & $1.61 \pm 0.28$ & $1.78 \pm 0.28^{* * *}$ \\
\hline$\Delta \mathrm{IC}$ isotime-rest, $\mathrm{L}$ & $-0.32 \pm 0.22$ & $-0.19 \pm 0.18^{* * *}$ & $0.14 \pm 0.23^{*}$ & $-0.06 \pm 0.26^{* * * * * *}$ \\
\hline Dyspneab $^{b}$ & $9.0(7.0-10)$ & $4.5(2.0-10)^{* * *}$ & $4.0(2.0-7.0)^{*}$ & $3.0(1.0-7.0)^{* * * *}$ \\
\hline$\Delta$ dyspnea BD-PL ${ }^{b}$ & & $-3.5(-6.0$ to -1.0$)$ & & $-1.0(-3.0 \text { to }-4.0)^{* * * *}$ \\
\hline Leg fatigue ${ }^{b}$ & $7(3-10)$ & $5(2-10)$ & $5(3-8)^{*}$ & $5(1-7)$ \\
\hline$\Delta$ leg fatigue $B D-P L^{b}$ & & $-1.5(-7.0$ to -5.0$)$ & & $-2.0(-3.0$ to -4.0$)$ \\
\hline \multicolumn{5}{|l|}{ End of exercise } \\
\hline Tlim, s & $423 \pm 170$ & $542 \pm 258^{* *}$ & $654 \pm 255^{*}$ & $783 \pm 261^{*, * *}$ \\
\hline Dyspneab $^{\mathrm{b}}$ & $9.0(7.0-10)$ & $7.5(1.0-10)$ & $4.5(2.0-7.0)^{*}$ & $4.5(1.0-9.0)$ \\
\hline Leg fatigue ${ }^{b}$ & $7.0(7.0-10)$ & $7.0(1.0-10)$ & $5.0(3.0-8.0)^{*}$ & $5.5(0.0-9.0)$ \\
\hline $\mathrm{SpO}_{2}, \%$ & $91 \pm 6$ & $92 \pm 5$ & $87 \pm 8$ & $89 \pm 9$ \\
\hline
\end{tabular}

PL: placebo; BD: bronchodilator; IC: inspiratory capacity; and Tlim: time to the limit of exercise tolerance. ${ }^{\text {a } V a l u e s}$ expressed as mean $\pm \mathrm{SD}$, except where otherwise indicated. bValues expressed as median (interquartile range). Modified Borg scale. ${ }^{*} p<0.05$ : intergroup variation at a given time point (PL or BD). ${ }^{* *} p<0.05$ : intraindividual variation (pre- vs. post-BD). ${ }^{* * *} p<0.05$ intergroup variation (pre- vs. post-BD). 

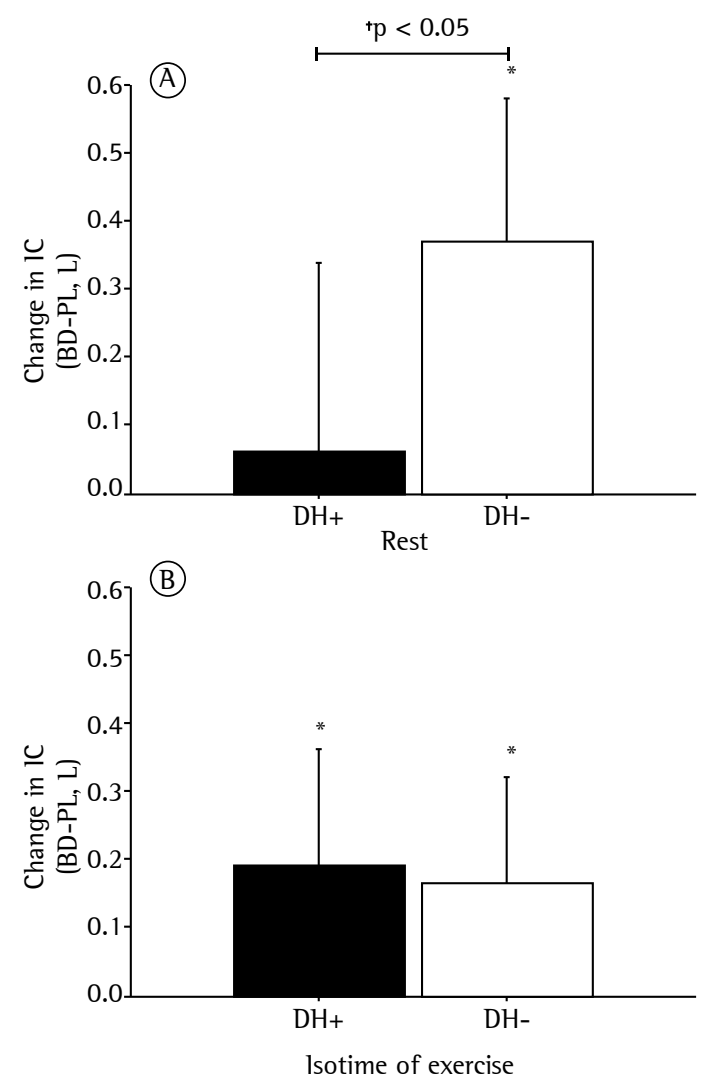

Figure 2 - Change in inspiratory capacity bronchodilatorplacebo (BD-PL) at rest (in A) and at isotime of exercise at constant speed (in B) in the groups of patients with dynamic hyperinflation $(\mathrm{DH}+)$ and without dynamic hyperinflation (DH-). *p $<0.05$; intragroup BD-PL difference. ${ }^{\dagger}$ Intergroup BD-PL difference.

rest and by reducing the rate of hyperinflation during exercise.

Given that DH plays a central role in limiting exercise in COPD patients, ${ }^{(1-3)}$ a reduction in $\mathrm{DH}$ after bronchodilator use ${ }^{(5)}$ (as evidenced by a significant increase in $1 \mathrm{C}$ at isotime; Figure 2B) was expected to result in increased Tlim in the $\mathrm{DH}+$ patients. Given that reduced DH has consistently been associated with increased endurance time, ${ }^{(6,17-}$ 19) the $\mathrm{DH}+$ patients were expected to have a more favorable pathophysiological substrate for bronchodilator activity and show significantly greater increases in Tlim when compared with the $\mathrm{DH}$ - patients. However, both groups showed similar improvements in Tlim after bronchodilator use (Figure 3). Although from a conceptual standpoint the $\mathrm{DH}$ - patients did not develop $\mathrm{DH}$, the significant increase in resting $\mathrm{IC}$ (Figure 2A)
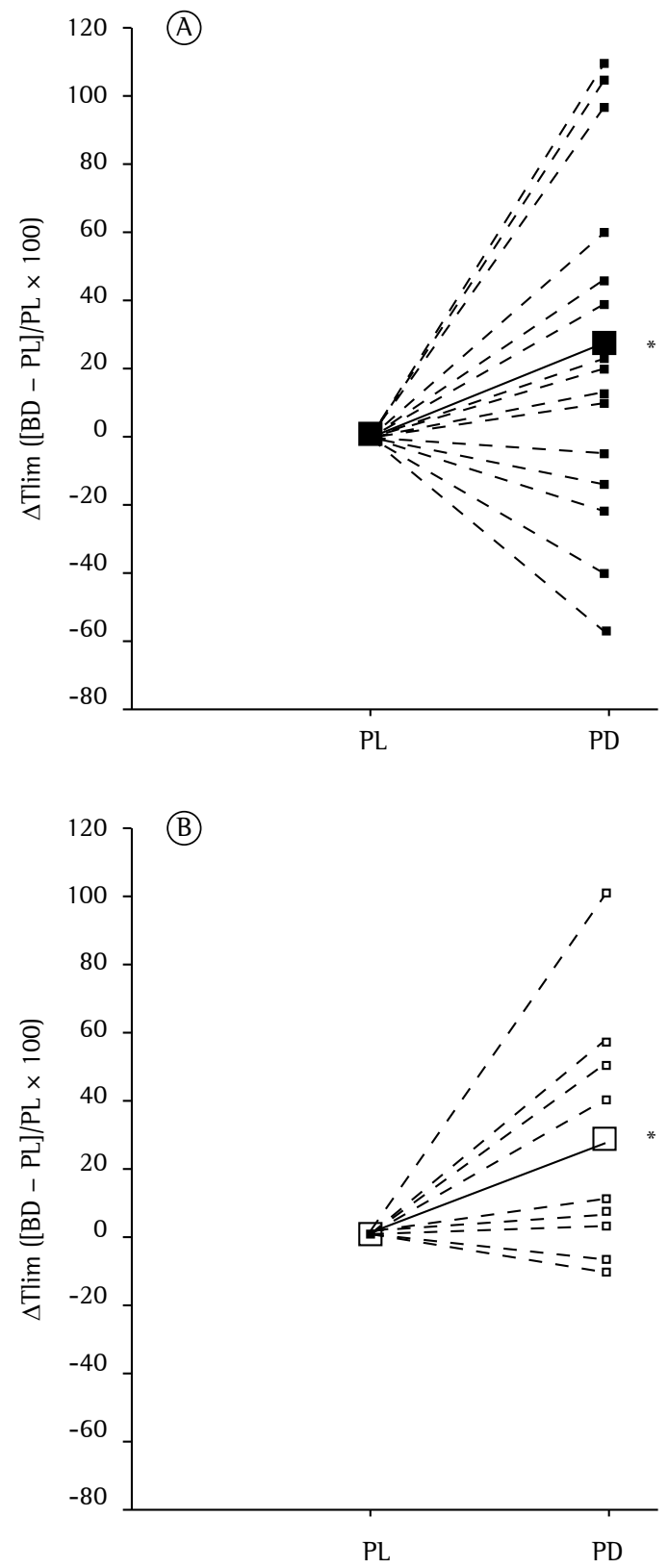

Figure 3 - Bronchodilator/placebo (BD-PL) change in exercise tolerance (Tlim) in the patients (dashed lines) with dynamic hyperinflation (in A) and without dynamic hyperinflation (in B). The solid lines represent the group means. ${ }^{*} p<0.05$; intragroup difference.

seems to have represented an important mechanism to explain improved exercise performance.

Resting $\mathrm{IC}$ has been identified as an important modulator of ventilatory capacity, breathing pattern, dyspnea on exertion, ${ }^{(11)}$ and $\mathrm{Tlim}^{(10,17)}$ in patients with COPD. This means that static lung volume measurements provide an estimate 
of the inspiratory reserve volume available for exercise, delaying a critical limitation in tidal volume expansion. ${ }^{(20)}$ Therefore, the development of ventilatory constraint seems to be the primary component influencing the pattern of respiratory response to exercise in patients with COPD. This important mechanic event during exercise marks the beginning of the progressive disparity between respiratory muscle effort (together with central nervous stimulation) and thoracic movement (neuromechanical dissociation), resulting in intolerable levels of dyspnea and in exercise termination. ${ }^{(20,21)}$ Therefore, a low $1 \mathrm{C}$ at rest (reflecting static lung hyperinflation) and a critical reduction in $1 \mathrm{C}$ during exercise (DH) can, in isolation or in combination, limit the ability to increase ventilation or reach a critical inspiratory reserve volume that, limited superiorly by TLC, does not allow a further increase in tidal volume. ${ }^{(11)}$

Previous studies (including a total of 100 patients) have shown that the pattern of $\mathrm{DH}$ influences exercise capacity. ${ }^{(22-25)}$ In contrast, Guenette et al. ${ }^{(26)}$ recently analyzed a total of 130 COPD patients (whose FEV1 values were similar to those observed in previous studies, i.e., $\approx 40-50 \%$ of predicted) and reported that the presence or absence of $\mathrm{DH}$ during exercise had no influence on the intensity of dyspnea or on exercise tolerance during high-intensity exercise. On the contrary, critical restriction of tidal volume expansion was shown to be the primary mechanism associated with those outcomes, independently of the presence of $\mathrm{DH}$. In addition, the reduction in dyspnea after bronchodilator therapy, hyperoxia, and physical training has been shown to occur independently of the reduction in the rate of $\mathrm{DH}^{(27-29)}$ Therefore, it is likely that other mechanical effects (including an absolute reduction in operating lung volumes with a delay in reaching a critical restriction of tidal volume expansion) occurring after these interventions are more important in explaining the improvement in dyspnea and exercise tolerance than is the small or inconsistent reduction in the rate of development of $\mathrm{DH}$. It is of note that the patients in the $\mathrm{DH}+$ group had higher dyspnea scores at isotime than did those in the $\mathrm{DH}$ - group. This finding is consistent with the concept that the magnitude of dyspnea is related to ventilation at increased operating volumes (reduced IC) and the resulting neuromechanical uncoupling. ${ }^{(20,21)}$
The mechanism whereby the $\mathrm{DH}$ - patients in the present study were able to achieve increased IC during exercise (in comparison with reduced $1 C$ at rest) after placebo administration remains unexplained. Similar results were obtained in a previous study, ${ }^{(30)}$ in which it was speculated that the abovementioned finding was due to lower expiratory airflow limitation in less severely ill patients, with a respiratory pattern of abdominal muscle recruitment during exercise and, consequently, reduced operating lung volumes. However, unlike the patients in the present study, the patients in that study showed lower Tlim after bronchodilator use than did those who were more severely ill and who had hyperinflation.

The main limitations of the present study include the fact that we evaluated a convenience sample, having recruited patients during a predetermined period (possibly resulting in insufficient statistical power to make certain comparisons), and the fact that we did not measure TLC. This means that the variations in lung volumes were estimated exclusively by $1 \mathrm{C}$, rather than by EELV (i.e., TLC/ IC). Although this limitation did not allow us to evaluate, in an adequate manner, possible differences in the baseline degree of positioning of operating lung volumes, this was minimized by the crossover design of the study, in which the same individuals were compared after two different interventions. In addition, we did not study patients with severe hypoxemia (resting $\mathrm{Sp0} 2<90 \%$ ), in whom the hypoxic drive can modulate the kinetics of $\mathrm{DH}$ development and the bronchodilator response. Therefore, our findings should not be extrapolated to such patients.

In conclusion, the heterogeneity of the pattern of development of DH during exercise does not seem to modulate the ability of patients with moderate to severe COPD to improve their exercise capacity after inhaled bronchodilator use. Therefore, increased exercise tolerance in $\mathrm{DH}$ - patients seems to be related to a bronchodilator-induced reduction in resting "static" lung hyperinflation. However, patients showing no deflation at rest could still benefit from bronchodilator use, provided that there is a decrease in the rate of development of DH during exercise. Clinically, these data demonstrate that measurements of $\mathrm{IC}$ at rest and during exercise are complementary in the evaluation of the mechanisms underlying the beneficial effects of bronchodilators in this population of patients. 


\section{References}

1. O’Donnell DE. Hyperinflation, dyspnea, and exercise intolerance in chronic obstructive pulmonary disease. Proc Am Thorac Soc. 2006;3(2):180-4. http://dx.doi. org/10.1513/pats.200508-093D0

2. O'Donnell DE, Revill SM, Webb KA. Dynamic hyperinflation and exercise intolerance in chronic obstructive pulmonary disease. Am J Respir Crit Care Med. 2001;164(5):770-7. http://dx.doi.org/10.1164/ajrccm.164.5.2012122

3. O'Donnell DE, Webb KA. The major limitation to exercise performance in COPD is dynamic hyperinflation. J Appl Physiol (1985). 2008;105(2):753-5. http://dx.doi. org/10.1152/japplphysiol.90336.2008b

4. O'Donnell DE. Assessment of bronchodilator efficacy in symptomatic COPD: is spirometry useful? Chest. 2000;117(2 Suppl):42S-7S. http://dx.doi.org/10.1378/ chest.117.2_suppl.42S

5. Casaburi R, Porszasz J. Reduction of hyperinflation by pharmacologic and other interventions. Proc Am Thorac Soc. 2006;3(2):185-9. http://dx.doi.org/10.1513/ pats.200508-095D0

6. Belman MJ, Botnick WC, Shin JW. Inhaled bronchodilators reduce dynamic hyperinflation during exercise in patients with chronic obstructive pulmonary disease. Am J Respir Crit Care Med. 1996;153(3): 967-75. http://dx.doi. org/10.1164/ajrccm.153.3.8630581

7. O'Donnell DE, Lam M, Webb KA. Measurement of symptoms, lung hyperinflation, and endurance during exercise in chronic obstructive pulmonary disease. Am. J. Respir Crit Care Med. 1998;158(5 Pt 1):1557-65. http:// dx.doi.org/10.1164/ajrccm.158.5.9804004

8. Yan S, Kaminski D, Sliwinski P. Reliability of inspiratory capacity for estimating end-expiratory lung volume changes during exercise in patients with chronic obstructive pulmonary disease. Am J Respir Crit Care Med. 1997;156(1):55-9. http://dx.doi.org/10.1164/ ajrccm.156.1.9608113

9. Stubbing DG, Pengelly LD, Morse JL, Jones NL Pulmonary mechanics during exercise in subjects with chronic airflow obstruction. J Appl Physiol Respir Environ Exerc Physiol. 1980;49(3):511-5.

10. Albuquerque AL, Nery LE, Villaça DS, Machado TY, Oliveira CC, Paes AT, et al. Inspiratory fraction and exercise impairment in COPD patients GOLD stages 11-111. Eur Respir J. 2006;28(5):939-44. http://dx.doi.org/10.118 3/09031936.06.00040506

11. O'Donnell DE, Guenette JA, Maltais F, Webb KA. Decline of resting inspiratory capacity in COPD: the impact on breathing pattern, dyspnea, and ventilatory capacity during exercise. Chest. 2012;141(3):753-62. http:// dx.doi.org/10.1378/chest.11-0787

12. Vestbo J, Hurd SS, Agustí AG, Jones PW, Vogelmeier C, Anzueto A, et al. Global strategy for the diagnosis, management, and prevention of chronic obstructive pulmonary disease: GOLD executive summary. Am J Respir Crit Care Med. 2013;187(4):347-65. http://dx.doi. org/10.1164/rccm.201204-0596PP

13. Neder JA, Andreoni S, Lerario MC, Nery LE. Reference values for lung function tests. 11. Maximal respiratory pressures and voluntary ventilation. Braz J Med Biol Res. 1999;32(6):719-27. http://dx.doi.org/10.1590/ S0100-879X1999000600007
14. Borg GA. Psychophysical bases of perceived exertion. Med Sci Sports Exerc. 1982;14(5):377-81. http://dx.doi. org/10.1249/00005768-198205000-00012

15. Johnson BD, Weisman IM, Zeballos RJ, Beck KC. Emerging concepts in the evaluation of ventilatory limitation during exercise: the exercise tidal flow-volume loop. Chest. 2009;116(2):488-503. http://dx.doi.org/10.1378/ chest.116.2.488

16. Pereira CA. Espirometria. J Pneumol. 2002;28(Suppl 3):S1-S82.

17. O’Donnell DE, Voduc N, Fitzpatrick M, Webb KA. Effect of salmeterol on the ventilatory response to exercise in chronic obstructive pulmonary disease. Eur Respir J. 2004;24(1):86-94. http://dx.doi.org/10.1183/0903 1936.04.00072703

18. Neder JA, Fuld JP, Overend T, Thirlwell J, Carter R, Stevenson R, et al. Effects of formoterol on exercise tolerance in severely disabled patients with COPD. Respir Med. 2007;101(10):2056-64. http://dx.doi.org/10.1016/j. rmed.2007.06.006

19. Berton DC, Reis M, Siqueira AC, Barroco AC, Takara LS, Bravo DM, et al. Effects of tiotropium and formoterol on dynamic hyperinflation and exercise endurance in COPD. Respir Med. 2010;104(9):1288-96. http://dx.doi. org/10.1016/j.rmed.2010.05.017

20. O'Donnell DE, Hamilton AL, Webb KA. Sensory-mechanical relationships during high-intensity, constant-work-rate exercise in COPD. J Appl Physiol 2006; 101(4): 1025-1035. http://dx.doi.org/10.1152/japplphysiol.01470.2005

21. Laveneziana P, Webb KA, Ora J, Wadell K, O'Donnell DE. Evolution of dyspnea during exercise in chronic obstructive pulmonary disease: impact of critical volume constraints. Am J Respir Crit Care Med. 2011;184(12):1367-73. http:// dx.doi.org/10.1164/rccm.201106-11280C

22. Aliverti A, Stevenson N, Dellacà RL, Lo Mauro A, Pedotti A, Calverley PM. Regional chest wall volumes during exercise in chronic obstructive pulmonary disease. Thorax. 2004;59(3):210-6. http://dx.doi.org/10.1136/ thorax.2003.011494

23. Vogiatzis 1 , Georgiadou 0 , Golemati S, Aliverti A, Kosmas E, Kastanakis E, et al. Patterns of dynamic hyperinflation during exercise and recovery in patients with severe chronic obstructive pulmonary disease. Thorax. 2005;60(9):723-9. http://dx.doi.org/10.1136/thx.2004.039115

24. Takara LS, Cunha TM, Barbosa P, Rodrigues MK, Oliveira MF, Nery LE, et al. Dynamics of chest wall volume regulation during constant work rate exercise in patients with chronic obstructive pulmonary disease. Braz J Med Biol Res. 2012;45(12):1276-83. http://dx.doi.org/10.1590/ S0100-879X2012001200024

25. Cordoni PK, Berton DC, Squassoni SD, Scuarcialupi ME, Neder JA, Fiss E. Dynamic hyperinflation during treadmill exercise testing in patients with moderate to severe COPD. J Bras Pneumol. 2012;38(1):13-23.

26. Guenette JA, Webb KA, O’Donnell DE. Does dynamic hyperinflation contribute to dyspnoea during exercise in patients with COPD? Eur Respir J. 2012;40(2):322-9. http://dx.doi.org/10.1183/09031936.00157711

27. O'Donnell DE, Lam M, Webb KA. Spirometric correlates of improvement in exercise performance after anticholinergic therapy in chronic obstructive pulmonary disease. Am J Respir Crit Care Med. 1999;160(2): 542-9. http://dx.doi. org/10.1164/ajrccm.160.2.9901038 
28. O'Donnell DE, McGuire M, Samis L, Webb KA. General exercise training improves ventilatory and peripheral muscle strength and endurance in chronic airflow limitation. Am J Respir Crit Care Med. 1998;157(5 Pt 1): 148997. http://dx.doi.org/10.1164/ajrccm.157.5.9708010

29. O'Donnell DE, Bain DJ, Webb KA. Factors contributing to relief of exertional breathlessness during hyperoxia in chronic airflow limitation. Am J Respir Crit Care
Med. 1997;155(2):530-5. http://dx.doi.org/10.1164/ ajrccm.155.2.9032190

30. Aliverti A, Rodger K, Dellacà RL, Stevenson N, Lo Mauro A, Pedotti A, et al. Effect of salbutamol on lung function and chest wall volumes at rest and during exercise in COPD. Thorax. 2005;60(11):916-24. http://dx.doi. org/10.1136/thx.2004.037937

\section{About the authors}

\section{Maria Enedina Aquino Scuarcialupi}

Professor. Paraíba School of Medical Sciences, João Pessoa, Brazil.

\section{Danilo Cortozi Berton}

Professor. Federal University of Rio Grande do Sul School of Medicine; and Pulmonologist. Porto Alegre Hospital de Clínicas, Porto Alegre, Brazil.

\section{Priscila Kessar Cordoni}

Assistant Professor. Department of Pulmonology, ABC School of Medicine, Santo André, Brazil.

\section{Selma Denis Squassoni}

Physiotherapist. Pulmonary Rehabilitation Division, Department of Pulmonology, ABC School of Medicine, Santo André, Brazil.

\section{Elie Fiss}

Full Professor. Department of Pulmonology, ABC School of Medicine, Santo André, Brazil.

\section{José Alberto Neder}

Professor of Respiratory Medicine. Division of Respiratory and Critical Care Medicine, Queen's University and Kingston General Hospital, Kingston, Canada; and Professor. Federal University of São Paulo, São Paulo, Brazil. 